\title{
RESEARCH
}

Open Access

\section{Thirty-three long-term survivors after cytoreductive surgery in patients with peritoneal metastases from colorectal cancer: a retrospective descriptive study}

Yasuyuki Kamada ${ }^{1,2,3^{*}}$ (D, Koya Hida ${ }^{1}$, Haruaki Ishibashi ${ }^{2,3}$, Shouzou Sako ${ }^{2,3}$, Akiyoshi Mizumoto ${ }^{4}$, Masumi Ichinose ${ }^{4}$, Naveen Padmanabhan ${ }^{3,5}$, Shinya Yoshida ${ }^{1}$ and Yutaka Yonemura ${ }^{2,3,4}$

\begin{abstract}
Background: Cytoreductive surgery (CRS) combined with hyperthermic intraperitoneal chemotherapy (HIPEC) improves survival in selected patients with peritoneal metastasis (PM) from colorectal cancer (CRC). However, little has been reported on characteristics and clinical course of long-term survivors with CRC-PM beyond 5 years. The objective of this study was to identify the clinical and oncological features affecting long-term survival of CRC-PM after comprehensive treatment.
\end{abstract}

Methods: Between January 1990 and April 2015, CRC-PM patients who underwent CRS with or without HIPEC in two Japanese tertiary hospitals were analyzed. Clinicopathological parameters and therapeutic details for long-term survivors (patients surviving $\geq 5$ years after CRS) were described and compared with those for non-survivors (patients surviving $<5$ years).

Results: The study identified 236 patients with CRC-PM who underwent CRS, with a median follow-up period of 2.5 years. Thirty-three patients (14.0\%) were considered as long-term survivors. Compared with non-survivors, longterm survivors had a lower median peritoneal cancer index (PCI) [4 (1-27) vs 9 (0-39), $p<0.001]$. Complete cytoreduction (CCR-0) was achieved in all long-term survivors, with a significantly higher rate [33/33 (100\%) vs 141/ $203(69.8 \%), p<0.001]$. Metachronous onsets of PM were more frequently observed in the long-term survivor group [26/33 (78.8\%) vs 103/203 (50.3\%), $p=0.018]$. Regarding histopathology, long-term survivors more frequently had mucinous adenocarcinoma than non-survivors [8/33 (24.2\%) vs 27/203 (13.3\%)] and less likely exhibited poorly differentiated or signet ring cell carcinoma [2/33 (6.1\%) vs 48/203 (23.7\%)] $(p<0.001)$.

Conclusions: One in seven patients with CRC-PM achieved the long-term milestone after CRS. A long-term survival was associated with the presence of low PCl, CCR-0, metachronous onset, and mucinous histology.

Keywords: Peritoneal metastasis, Colorectal cancer, Long-term survivors, Cytoreductive surgery, HIPEC

\footnotetext{
* Correspondence: y_kamada@kuhp.kyoto-u.ac.jp

'Department of Surgery, Graduate School of Medicine, Kyoto University, 54, Shogoin-Kawahara-Cho, Sakyo-Ku, Kyoto, Japan

${ }^{2} \mathrm{NPO}$ to support Peritoneal Surface Malignancy Treatment, Japanese/Asian School of Peritoneal Surface Oncology, Kyoto, Japan

Full list of author information is available at the end of the article
}

(c) The Author(s). 2021 Open Access This article is licensed under a Creative Commons Attribution 4.0 International License, which permits use, sharing, adaptation, distribution and reproduction in any medium or format, as long as you give appropriate credit to the original author(s) and the source, provide a link to the Creative Commons licence, and indicate if changes were made. The images or other third party material in this article are included in the article's Creative Commons. licence, unless indicated otherwise in a credit line to the material. If material is not included in the article's Creative Commons licence and your intended use is not permitted by statutory regulation or exceeds the permitted use, you will need to obtain permission directly from the copyright holder. To view a copy of this licence, visit http://creativecommons.org/licenses/by/4.0/ The Creative Commons Public Domain Dedication waiver (http://creativecommons.org/publicdomain/zero/1.0/) applies to the data made available in this article, unless otherwise stated in a credit line to the data. 


\section{Introduction}

Colorectal cancer (CRC) represents the third most frequent cancer diagnosis and second most frequent cause of cancer-related mortality throughout the world [1]. An estimated $2-4 \%$ of patients have synchronous peritoneal metastasis (PM) [2-4], and approximately $20 \%$ develop metachronous PM during the course of their disease [5]. PM was traditionally considered a terminal event, and patients were palliated with chemotherapy or minor surgical procedures. The overall estimated survival in untreated cases was 6 months $[2,6,7]$, whereas with contemporary systemic chemotherapy, the median overall survival (OS) has been prolonged to 20 months [8-10].

Over the past two decades, several centers worldwide have adopted extensive cytoreductive surgery (CRS) and hyperthermic intraperitoneal chemoperfusion (HIPEC), aiming for cure in patients with PM. With this approach, long-term survival has been reported in CRC-PM, with a median OS of 20-63 months [11-20]. A randomized trial proved the survival benefit in CRC-PM patients undergoing CRS/HIPEC over systemic chemotherapies [21], although the study encountered the criticism that the study cohort included appendiceal primary carcinoma, which is biologically different from CRC.

Selecting the appropriate candidates for CRS and HIPEC is vital to achieve long-term survival in CRC patients with PM. Several studies revealed the various features associated with survival benefits in detail [22-26], although there has been little research which focused on long-term survivors diagnosed with CRC-PM. Additionally, 5-year survival probabilities were estimated in most of the past studies.

The data on oncologic outcomes in CRC-PM patients surviving beyond 5 years are sparse. Therefore, the aim of this study is to describe the characteristics of longterm survivors among patients with PM from CRC, with the goal of finding clinical and pathological factors associated with survival longer than 5 years after CRS.

\section{Methods}

\section{Patients}

This was a retrospective study of CRC-PM patients who had undergone CRS with or without HIPEC in two Japanese tertiary hospitals. Inclusion criteria were the following: (1) histopathologically proven PM from CRC and (2) treated with CRS between January 1990 and April 2015. Exclusion criteria were the following: (1) PM from appendiceal carcinoma, (2) treated with only systemic chemotherapy, and (3) followed-up less than 5 years but alive at the last encounter. We identified and stratified into the two groups based on OS: long-term survivors (who lived at least 5 years after the first CRS) and non-survivors (who died within 5 years). We then described the characteristics of long-term survivors in detail, and moreover, compared the factors among the two groups.

Patients who had a recurrence-free survival (RFS) $\geq 5$ years after the last operation for metastases were considered as cured patients. Because there is no official definition of a long-term survival and cure in CRC-PM patients, we used an OS and RFS of $\geq 5$ years as our criteria.

\section{Surgical treatment and intraperitoneal chemotherapy}

The suitability of CRS and HIPEC was decided based on the consensus of a multidisciplinary team. Patients as follows were not eligible for CRS and HIPEC: ECOG performance status of more than 2 , serious comorbidities, unresectable metastasis other than PM, and severe PM not amenable to curative intent resection.

All patients were treated by cytoreduction according to the Sugarbaker technique after intraperitoneal exploration [27]. The extent of intraoperative tumor volume was measured using the peritoneal cancer index (PCI) described by Jaquet and Sugarbaker [28]. PCI after January 1997 was prospectively recorded, while in the cases before 1997, estimated PCI was measured using operation records and pathological reports. The intent of CRS was to remove all visible intraperitoneal disease (completeness of cytoreduction). At the completion of surgery, the completeness of cytoreduction (CCR) score was recorded [28]: CCR-0 (no residual macroscopic tumor), CCR-1 (residual tumor deposits $<2.5 \mathrm{~mm}$ in diameter), and CCR-2 (residual tumor deposits $>2.5 \mathrm{~mm}$ in diameter). After completing CRS (CCR-0 or CCR-1), HIPEC was performed with the open coliseum technique with $4 \mathrm{~L}$ of physiological saline $(0.9 \%)$ as perfusate [29]. The target temperature was $42.5-43.5^{\circ} \mathrm{C}$, and treatment time was $30-60 \mathrm{~min}$. The drug regimen varied based on patient factors and prior neoadjuvant therapies. Commonly, 5-fluorouracil (5-FU), oxaliplatin, mitomycin C, and cisplatin were used alone or in combination. HIPEC was not performed in patients induced to poor general conditions after CRS due to a severe surgical stress (e.g., massive bleeding, prolonged operative time) and/or patient comorbidities. Major surgical complications within 30 days after CRS were defined as any intra- or extraabdominal event with a grade $\geq$ III according to the Clavien-Dindo classification [30].

\section{Data collection}

Between January 1997 and April 2015, the prospective institutional database was searched to identify eligible patients. A standard data form before 1997 was retrospectively completed. The data comprised the following: onset of PM, primary tumor location, histology, lymph node metastasis, KRAS, BRAF, PCI, CCR, HIPEC drug, postoperative complications, preoperative 
and postoperative chemotherapy, site of first recurrence, RFS, reoperation for recurrence, PCI and CCR at reoperation, and OS. The primary tumor located in the cecum, ascending colon, or transverse colon was defined as right-sided colon cancer, and those located in the splenic flexure, descending colon, or sigmoid colon were defined as left-sided colon cancer. Followup involved a clinical examination, tumor marker measurement, and imaging when required, every 3 months in the first 2 years, every 6 months for the next 3 years, and annually thereafter until any oncological event. The details of recurrence and consequent management details were noted, and follow-up frequency was modified based on the last event.

This retrospective study was approved by the ethics review committee for clinical studies of our institution. Our study was performed in accordance with the ethical guidelines of the Declaration of Helsinki. The patients involved in this study provided written informed consent authorizing the use and disclosure of their protected health information.

\section{Statistical analysis}

The closing date of follow-up for this study was the 30 April 2020. Using the Kaplan-Meier method, OS was calculated from the date of the first CRS for PM until the patient's death or last follow-up, and RFS was measured from the date of CRS until the date of first recurrence or last follow-up, including death. Continuous variables were given as median (range). Categorical data are given as frequencies and proportions. Chi-squared test or Fisher's exact test was used in categorical variables where appropriate, and Wilcoxon two sample test in continuous variables. A two tailed $p$ value $<0.05$ was considered significant. Variables proved to be significant by univariate analysis were included in multivariate logistic regression model. All statistical analyses were conducted by JMP statistical software version 14 (SAS Institute, Cary, NC).

\section{Results}

\section{Study population}

Between January 1990 and April 2015, 236 patients underwent CRS with or without HIPEC for CRC-PM, with a median follow-up time of 2.5 years. The median survival time was 1.6 years. The cohort predominantly consisted of females (55.1\%), and the median age was 59 years (range, 24-80). The median PCI of this cohort was 9 (range, 0-39). Of these patients, 33 patients (14.0\%) were classified as long-term survivors. Laparoscopic exploration or exploratory laparotomy was not performed in most cases.

\section{Description of long-term survivors \\ Patients' characteristics}

The demographics of long-term survivors are summarized in Table 1. The group consisted of 21 women and 12 men, with a median age of 59 (range, 33-75) years. The onset of PM was synchronous in 7 patients and metachronous in 26 patients. The primary tumor was located in the right colon in 17 patients and in the left colon in 16 patients. None of the patients had a primary tumor in the rectum. Histological diagnoses were well to moderately differentiated tubular adenocarcinoma, mucinous adenocarcinoma (MC), and signet ring cell carcinoma (SRCC) in 24, 7, and 2 cases, respectively. Lymph node metastases were observed on pathology in 21 patients. The status of mutation in KRAS and BRAF were examined in 15 and 5 patients, respectively. KRAS mutations were observed in 4/15 (26.7\%) and BRAF in 0/5 (0\%). The median PCI in long-term survivors was 4 (range, 1-27). Categorizing PCI in this group, 28 patients $(84.8 \%)$ had PCI $<10,4(12.1 \%)$ had PCI 10-19, and 1 patient (3.1\%) had PCI $\geq 20$. The median PCI of the cured subgroup was 2 (range, 1-8). Among the 16 cured patients, 15 patients (93.8\%) had PCI 1-5.

\section{Treatment factors}

Table 1 shows the treatment factors of long-term survivors. Most of the patients received systemic chemotherapy: $28(84.8 \%)$ of the 33 patients received preoperative and postoperative chemotherapy. Modern chemotherapy agents (fluorinated pyrimidine plus oxaliplatin or irinotecan, \pm bevacizumab or panitumumab) were used in 22 patients $(66.7 \%)$ receiving preoperative regimens and in 12 patients $(36.4 \%)$ receiving postoperative regimens. Five patients underwent preoperative intraperitoneal chemotherapy with cisplatin and/or docetaxel.

CCR-0 was achieved in all 33 patients, and 26 patients received HIPEC. Seven patients did not undergo HIPEC because of deterioration of their general condition secondary to massive bleeding during the CRS procedure. The HIPEC regimens were cisplatin plus mitomycin $\mathrm{C}$ in 18 patients, 5-FU plus oxaliplatin in 7 patients, and mitomycin $\mathrm{C}$ plus 5 -FU in 1 patient. Among the longterm survivors, there was no significant difference in OS and RFS between HIPEC and non-HIPEC groups (OS, $p=0.302$; RFS, $p=0.445$ ).

Three patients of 33 long-term survivors experienced major intra-abdominal complications, and two experienced major extra-abdominal complications (grades III or IV).

\section{Patient outcomes}

Patients' prognoses are presented in Table 2, and a flow chart is shown in Fig. 1. The 14 patients who did not develop recurrence after the first CRS and the 2 patients who survived at least 5 years after the last operation 


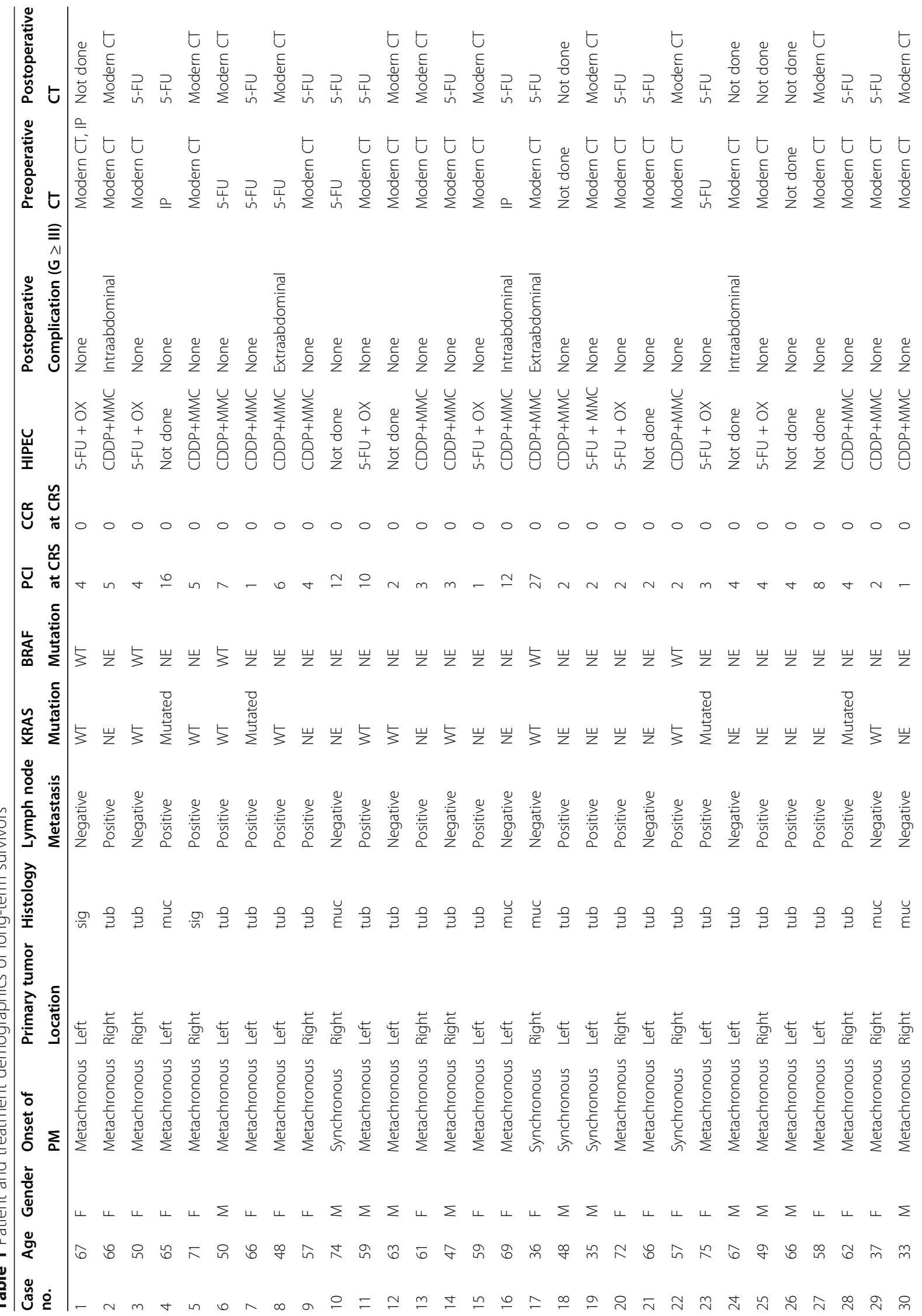




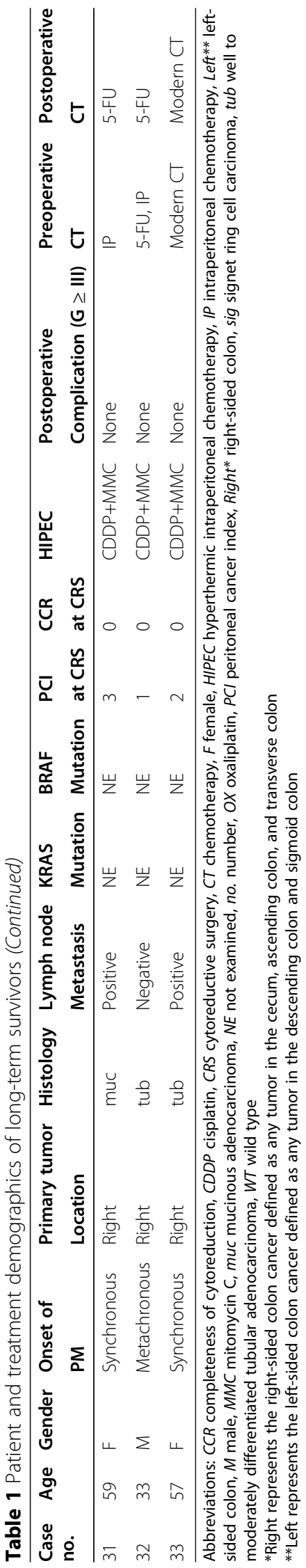




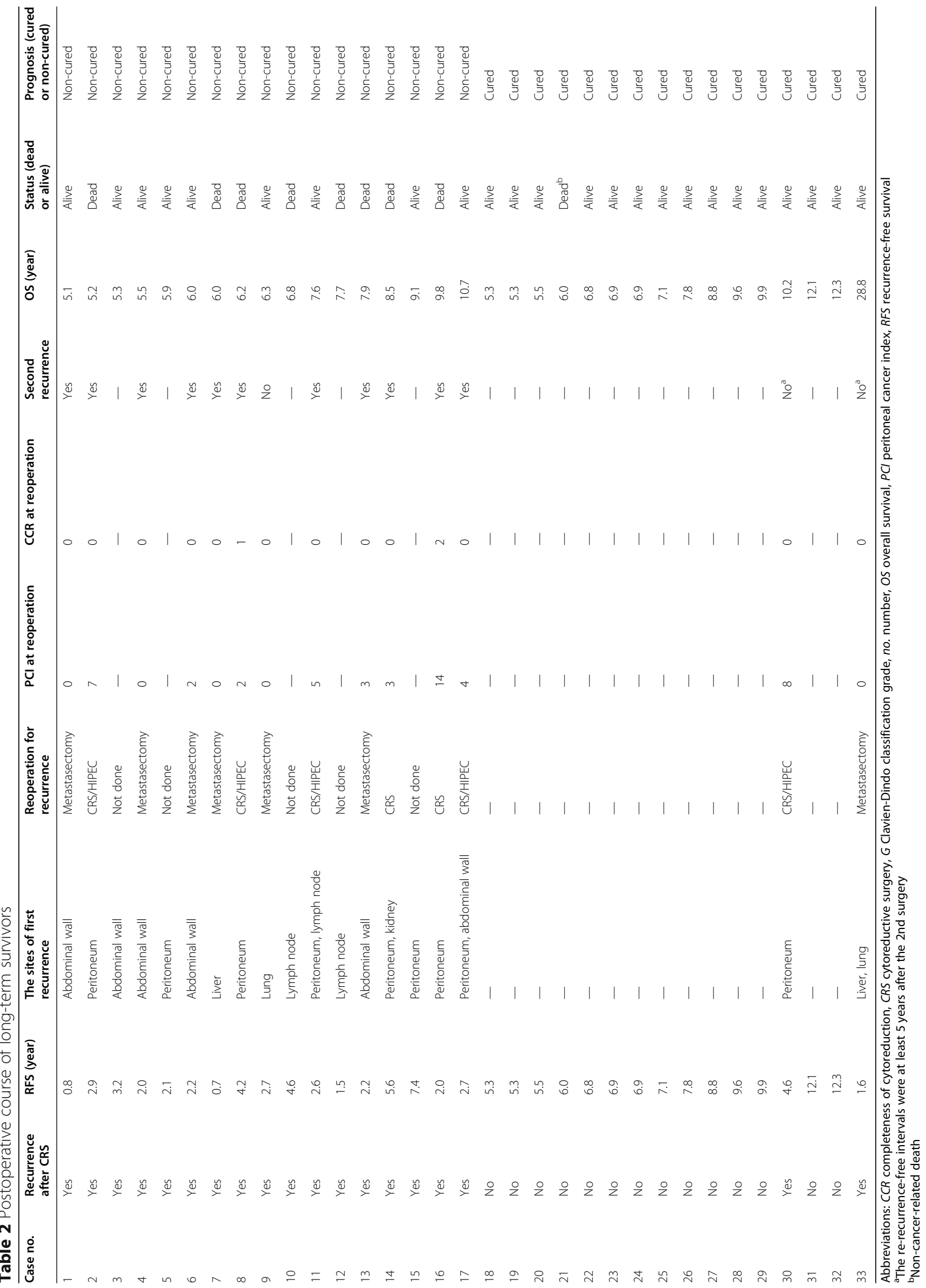




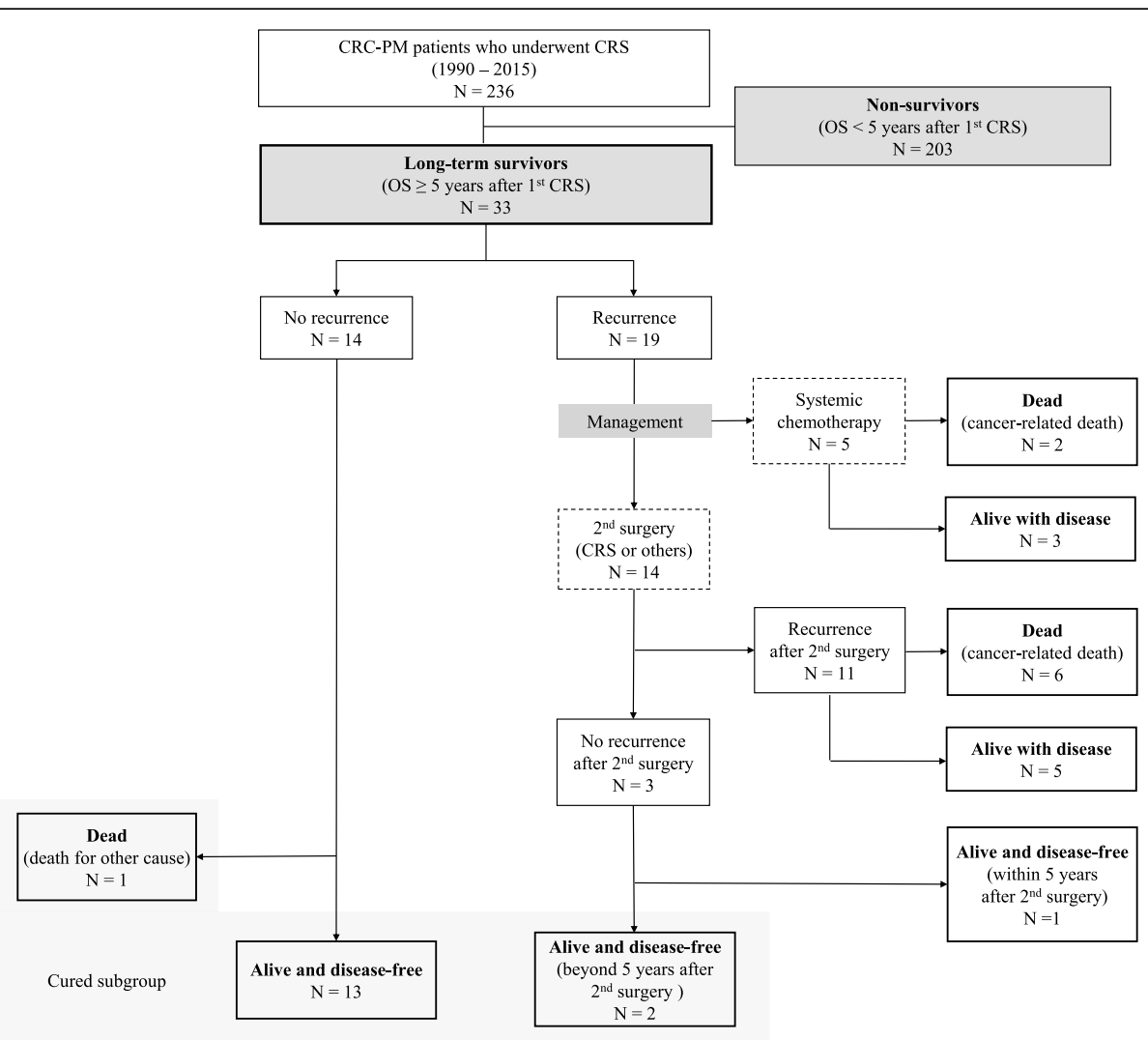

Fig. 1 Flow diagram of patient enrollment. Abbreviations: CRC colorectal cancer, CRS cytoreductive surgery, OS overall survival, PM peritoneal metastasis

without a second recurrence were considered "cured." The patient characteristics between cured and noncured patients are compared in Table 3. Among the long-term survivors, 5 patients survived beyond 10 years after the first CRS.

Tumor recurrence occurred in 19/33 cases at a median of 2.6 (range, 0.7-7.4) years. Among 19 patients with recurrence, 16 received HIPEC at the first CRS. The site of first recurrence included the peritoneum $(n=9)$, abdominal wall $(n=6)$, lymph nodes $(n=3)$, liver $(n=2)$, lung $(n=2)$, and kidney $(n=1)$. In this group of 19 patients with recurrence after CRS, 5 were treated with palliative systemic therapy and 14 with a second surgical procedure; 7 in metastasectomy, 5 in CRS/HIPEC, and 2 in CRS. Median PCI in the second operation was 2 (range, 0-14). Twelve patients achieved CCR-0, and one each achieved CCR-1 and CCR-2. In the group who underwent secondary cytoreduction or metastasectomy, 11 developed a second recurrence. Among these 11 patients with re-recurrences, 6 patients died of a cancerrelated cause, and 5 patients were alive with disease at the last follow-up.

\section{Comparison between long-term survivors and non- survivors}

The patient characteristics of 33 long-term survivors and 203 non-survivors are compared in Table 4 . Metachronous onsets of PM were more frequent in the long-term survivor group [26/33 (78.8\%) vs 103/ 203 (50.3\%), $p=0.018$ ]. Long-term survivors more frequently had MC than non-survivors [8/33 (24.2\%) vs $27 / 203(13.3 \%)$ ], and in addition, less likely presented with poorly differentiated or SRCC [2/33 $(6.1 \%)$ vs $48 / 203(23.7 \%)](p<0.001)$. The median PCI was significantly lower in long-term survivors $[4(1-27)$ vs 9 (0-39), $p<0.001]$. CCR-0 was achieved in 174 of total 236 CRC-PM patients, with a significantly higher rate in long-term survivors [33/33 (100\%) vs 141/203 (69.8\%), $p<0.001$ ]. Lymph node metastases were observed in 20/33 long-term survivors (60.6\%) and in 136/203 non-survivors $(67.0 \%)(p=0.553)$. HIPEC administration did not differ significantly between long-term survivors and non-survivors $[26 / 33(78.8 \%)$ vs $142(70.0 \%), p=$ 0.407]. 
Table 3 Clinicopathological characteristics between patients cured or non-cured

\begin{tabular}{llll}
\hline & Total $(\boldsymbol{n}=\mathbf{3 3})$ & Non-cured $(\boldsymbol{n}=\mathbf{1 7})$ & Cur \\
\hline $\begin{array}{l}\text { Age, year, median (range) } \\
\text { Gender, } \boldsymbol{n}\end{array}$ & $59(33-75)$ & $59(36-74)$ & 58.5 \\
$\quad$ Male & 12 & 5 & 7 \\
$\quad$ Female & 21 & 12 & 9 \\
Timing of peritoneal metastasis, $\boldsymbol{n}$ & & & 5 \\
$\quad$ Synchronous & 7 & 2 & 11 \\
$\quad$ Metachronous & 26 & 15 & 9 \\
Primary tumor location, $\boldsymbol{n}$ & & & 7 \\
$\quad$ Right colon & 17 & 8 & 0 \\
$\quad$ Left colon & 16 & 9 & 0 \\
$\quad$ Rectum & 0 & &
\end{tabular}

\section{Histology, $n$}

$\begin{array}{ll}\text { tub } & 24 \\ \text { muc } & 7 \\ \text { sig } & 2\end{array}$

sig

Lymph node metastasis, $n$

$$
\text { Negative }
$$

Positive

$\mathrm{PCl}$ at CRS, median (range)

$$
\begin{aligned}
& 0-5 \\
& 6-10 \\
& 11-15 \\
& 16-20 \\
& \geq 21
\end{aligned}
$$

\section{Completeness of cytoreduction}

CCR-0

CCR-1 to 3

HIPEC, $n$

$$
\text { Yes }
$$

No

Postoperative complication ( $G \geq 3$ )

$$
\text { Yes }
$$

No

Preoperative systemic chemotherapy, $n$

Yes

No

Preoperative intraperitoneal chemotherapy, $n$

$\begin{array}{ll}\text { Yes } & 5 \\ \text { No } & 28\end{array}$

Postoperative chemotherapy, $n$

$\begin{array}{ll}\text { Yes } & 28 \\ \text { No } & 5\end{array}$

Recurrence, $n$

12

21

25

4
4 (1-27)
Abbreviations: CCR completeness of cytoreduction, CRS cytoreductive surgery, G Clavien-Dindo classification grade, HIPEC hyperthermic intraperitoneal chemotherapy, muc mucinous adenocarcinoma, $P C I$ peritoneal cancer index, sig signet ring cell carcinoma, tub well-differentiated tubular adenocarcinoma 
Table 4 Clinicopathological characteristics of long-term survivors and non-survivors

\begin{tabular}{|c|c|c|c|c|c|}
\hline & & Non-survivors & Univariate & Multivariate & \\
\hline & $\begin{array}{l}\text { survivors } \\
(n=33)\end{array}$ & & $p$ value & OR $(95 \% \mathrm{Cl})$ & $p$ value \\
\hline Age, year, median (range) & $59(33-75)$ & $58(24-80)$ & 0.429 & & \\
\hline Gender, $n(\%)$ & & & 0.287 & & \\
\hline Male & $12(36.4)$ & $94(46.3)$ & & & \\
\hline Female & $21(63.6)$ & $109(53.7)$ & & & \\
\hline Timing of PM, $n$ (\%) & & & 0.003 & & 0.018 \\
\hline Synchronous & $7(21.2)$ & $100(49.3)$ & & Reference & \\
\hline Metachronous & $26(78.8)$ & $103(50.7)$ & & $3.10(1.14,8.39)$ & \\
\hline Primary tumor location, $n$ (\%) & & & 0.753 & & \\
\hline Right colon & $16(48.5)$ & $102(50.3)$ & & & \\
\hline Left colon & $17(51.5)$ & $98(48.3)$ & & & \\
\hline Rectum & $0(0)$ & $3(1.5)$ & & & \\
\hline Histology, $n$ (\%) & & & 0.036 & & $<0.001$ \\
\hline tub & $23(69.7)$ & $128(63.1)$ & & $11.86(2.88,48.82)$ & \\
\hline muc & $8(24.2)$ & $27(13.3)$ & & Reference & \\
\hline por or sig & $2(6.1)$ & $48(23.7)$ & & $0.031(0.004,0.228)$ & \\
\hline Lymph node metastasis, $n$ (\%) & & & 0.553 & & \\
\hline Negative & $13(39.4)$ & $67(33.0)$ & & & \\
\hline Positive & $20(60.6)$ & $136(67.0)$ & & & \\
\hline $\mathrm{PCl}$ at CRS, median (range) & $4(1-27)$ & $9(0-39)$ & $<0.001$ & $0.001(1.68 \mathrm{E}-05,0.055)$ & $<0.001$ \\
\hline Completeness of cytoreduction, $n$ (\%) & & & $<0.001$ & & $<0.001$ \\
\hline CCR-0 & $33(100)$ & $141(69.8)$ & & Reference & \\
\hline CCR-1 to 3 & $0(0)$ & $61(30.2)$ & & $8.19 E+07(0.00,-)$ & \\
\hline HIPEC, $n(\%)$ & & & 0.407 & & \\
\hline Yes & $26(78.8)$ & $142(70.0)$ & & & \\
\hline No & $7(21.2)$ & $61(30.1)$ & & & \\
\hline Postoperative complocation ( $G \geq 3$ ), $n$ (\%) & & & 0.199 & & \\
\hline Yes & $5(15.2)$ & $53(26.2)$ & & & \\
\hline No & $28(84.9)$ & $150(73.9)$ & & & \\
\hline Preoperative systemic chemotherapy, $n$ (\%) & & & 0.147 & & \\
\hline Yes & $28(84.9)$ & $190(93.6)$ & & & \\
\hline No & $5(15.2)$ & $13(6.4)$ & & & \\
\hline Postoperative chemotherapy, $n(\%)$ & & & 0.820 & & \\
\hline Yes & $27(81.8)$ & $158(77.8)$ & & & \\
\hline No & $6(18.2)$ & $45(22.2)$ & & & \\
\hline
\end{tabular}

Taken together, age, gender, primary tumor location, lymph node metastasis, HIPEC administration, postoperative complication (grade $\geq \mathrm{III}$ ), preoperative systemic chemotherapy, and postoperative chemotherapy were similar between the two groups. Univariate analysis demonstrated four variables (onset of PM, histology, PCI, CCR) to be significantly associated with $\mathrm{OS} \geq 5$ years. Multivariate analysis was carried out on these four factors, and all the factors were found to be significant factors for long-term survival.

\section{Discussion}

In our cohort of patients with CRC-PM who underwent extensive CRS and perioperative chemotherapy including systemic and intraperitoneal chemotherapy, 14.0\% (33/ 236) survived beyond 5 years. Sixteen of 33 patients 
remained recurrence-free more than 5 years after the last surgery for metastases and were considered "cured." Additionally, 5 patients in this cohort survived more than 10 years. Our study proves that long-term survival and cured status are possible in an appropriately selected sub-set of patients with PM from CRC.

Despite the adoption of CRS and HIPEC in many centers worldwide, this approach is still met with criticism. One of the arguments against CRS and HIPEC is high morbidity and mortality risk of these procedures [3133]. However, whether patients with PM from CRC can attain equivalent long-term survival with systemic therapy alone is doubtful [8-10]. A comprehensive approach with a combination of neoadjuvant systemic chemotherapy, CRS/HIPEC, and adjuvant systemic therapy may provide long-term survival in CRC-PM patients. This retrospective study was conducted to evaluate the characteristics of long-term survivors diagnosed with CRCPM who underwent CRS with or without HIPEC. Kaplan-Meier survival analyses tend to overestimate survival rate due to the effect of censor before the end of observation. By contrast, results from this present study provide specific and actual information on long-term outcome for CRC-PM patients. Although we only analyzed selected patients, understanding the results of our study may help improve outcomes in CRC-PM patients.

First, OS in CRC-PM patients treated with CRS is strongly associated with achieving complete cytoreduction. Several studies showed that patients with complete cytoreduction (CCR-0 or CCR-1) have a better survival outcome than patients with incomplete cytoreduction (CCR-2 or CCR-3) [34-36]. Others reported survival differences between CCR-0 and CCR-1 in CRC-PM patients [37]. In our study, all 33 patients received CCR-0 resection, and CCR- 0 was demonstrated to be an independent prognostic factor for long-term survival. These results reaffirm that complete cytoreduction with no macroscopic disease is important to achieve long-term survival.

Second, PCI, which describes the extent and distribution of peritoneal disease, is one of the most important prognostic indices. Several investigators have suggested that better outcomes are obtained after CRS and HIPEC with a PCI $<10[38,39]$, and worse survival with a PCI $>17$ [40, 41]. In our study, the median PCI in long-term survivors was significantly lower than in non-survivors. Moreover, all patients in the cured subgroup had a PCI $\leq 8$. However, it is also noteworthy that we identified a subset of long-term survivors with a PCI $>15$. While these findings confirmed the notion that $\mathrm{PCI}$ can be useful to predict outcome, a high PCI cannot entirely exclude the possibility of long-term survival.

Third, the current study showed that histopathology of CRC was related to long-term survival. In the group of long-term survivors, 7 patients had $\mathrm{MC}$, and 2 had SRCC. Histological differences between mucinous and non-mucinous regarding prognosis are controversial. Some investigators suggested that mucinous carcinoma patients had a worse prognosis $[42,43]$ while others did not $[44,45]$. Interestingly, we identified $M C$ as being associated with the actual long-term survival. Meanwhile, the negative impact of SRCC in CRC-PM has been described in multiple studies, with the median OS in these patients ranging from 7 to 13 months even if patients are treated with CRS and HIPEC [36, 46-49]. In this present study, a long-term survivor group less likely showed SRCC. However, two patients with SRCC achieved a 5-year survival. The proportion of SRCC patients who are eligible for CRS and consequently experience long-term survival is currently low. More detailed reporting and further research are required to identify potential long-term survivors.

Fourth, it was surprising to discover that the present study identified metachronous PM as being associated with long-term survival in patients with CRC-PM. A possible explanation is that disease progression of synchronous PM is considered aggressive. In contrast, two previous studies have shown that onset of PM does not affect OS $[23,50]$, but little evidence is available with regard to impact of timing when CRC-PM occurred. Information on onset of PM is preoperatively available while most prognostic factors for survival outcome in CRCPM patients are determined in the operating room. Whether metachronous onset of colorectal PM or not might be helpful in predicting long-terms survival.

Fifth, patients who had lymph node metastases constituted more than one-half of long-term survivors and the subgroup of cured patients. It has been proposed that regional lymph node metastasis has a negative prognostic impact on survival $[37,51-53]$. The recently developed COMPASS (colorectal peritoneal metastases prognostic surgical score) reported by Simkens et al. includes nodal status among the four clinical factors (PCI, nodal status, histology, and age) used to predict outcomes after CRS and HIPEC in CRC-PM [54]. However, lymph node meatastases in isolation cannot be considered an exclusion criterion [39]. With standardization of techniques for total mesorectal excision and complete mesocolic excision, which removes tumors en bloc with lymphatics, local recurrence has decreased [55, 56]. Among the long-term survivor group, the majority $(21 / 33,63.6 \%)$ of patients presented with lymph node metastases, and 10 of 21 patients were categorized into the cured subgroup. There was no statistically significant difference regarding nodal status between long-term survivors and nonsurvivors. At least, it is reasonable to support that CRCPM patients with lymph node metastasis can achieve long-term survival and cure. 
Finally, we found that HIPEC was not associated with long-term survival. The recent randomized control trial (PRODIGE-7) questioned the role of HIPEC with oxaliplatin in the clinical management of PM from CRC [57]. Although our findings are in agreement with the results of the trial, the present study does not necessarily support the ineffectiveness of HIPEC. We did not perform HIPEC in patients with poor general condition after CRS, due to a severe surgical stress and/or patient comorbidities. These patients without HIPEC tended to exhibit severe extent of peritoneal diseases and to have poor prognoses. Further studies should be required to elucidate whether HIPEC affects survival outcomes in patients with CRC-PM.

This study had several major limitations. First, because our study was retrospective in design, selection biases were introduced, due to the exclusion of patients with unresectable PM. Second, as a descriptive study, this current research lacked any comparison of control groups for statistical analysis of effectiveness of CRS/ HIPEC. Third, the definition of long-term survival and cure is not officially defined and was based only on survival times. Finally, we may not have detected some other differences because the total number of long-term survivors is small. However, the data in this study allowed a detailed assessment of the clinical features among CRC-PM patients.

\section{Conclusions}

Although CRC-PM is a challenging disease, one in seven patients actually achieved a 5-year survival after CRS. Low PCI, CCR-0, metachronous onset, and mucinous histology were associated with a higher likelihood of survivorship. It is important to continue identifying longterm survivors who enjoy the benefit of CRS.

\section{Abbreviations}

CCR: Complete cytoreduction; CRC: Colorectal cancer; CRS: Cytoreductive surgery; FU: Fluorouracil; HIPEC: Hyperthermic intraperitoneal chemotherapy; MC: Mucinous adenocarcinoma; OS: Overall survival; PCI: Peritoneal cancer index; PM: Peritoneal metastasis; RFS: Recurrence-free survival; SRCC: Signet ring cell carcinoma

\section{Acknowledgements}

Not applicable

\section{Authors' contributions}

YK and $Y Y$ designed the study. YK, YY, HI, SS, AM, and MI performed the data acquisition. YK, SY, and KH performed the data analysis and interpretation. YK and NP prepared the manuscript. KH and YY revised the paper critically. The authors read and approved the final manuscript.

\section{Funding}

None

\section{Availability of data and materials}

All data are available without restriction. Researchers can obtain data by contacting the corresponding author.

\section{Ethics approval and consent to participate}

This study of was approved by the institutional review boards and was also conducted in accordance with the Declaration of Helsinki, and all patients signed the informed consent.

\section{Consent for publication}

Not applicable.

\section{Competing interests}

The authors declare that they have no competing interests.

\section{Author details}

'Department of Surgery, Graduate School of Medicine, Kyoto University, 54, Shogoin-Kawahara-Cho, Sakyo-Ku, Kyoto, Japan. ${ }^{2} \mathrm{NPO}$ to support Peritoneal Surface Malignancy Treatment, Japanese/Asian School of Peritoneal Surface Oncology, Kyoto, Japan. ${ }^{3}$ Department of Regional Cancer Therapy, Peritoneal Surface Malignancy Center, Kishiwada Tokushukai Hospital, Kishiwada, Japan. ${ }^{4}$ Department of Regional Cancer Therapy, Peritoneal Surface Malignancy Center, Kusatsu General Hospital, Shiga, Japan. ${ }^{5}$ Department of Surgical Oncology, Apollo Cancer Institute, Chennai, India.

Received: 4 November 2020 Accepted: 20 January 2021

Published online: 28 January 2021

\section{References}

1. Bray F, Ferlay J, Soerjomataram I, Siegel RL, Torre LA, Jemal A. Global cancer statistics 2018: GLOBOCAN estimates of incidence and mortality worldwide for 36 cancers in 185 countries. CA Cancer J Clin. 2018;68:394-424.

2. Jayne DG, Fook S, Loi C, Seow-Choen F. Peritoneal carcinomatosis from colorectal cancer. Br J Surg. 2002;89:1545-50.

3. Lemmens VE, Klaver YL, Verwaal VJ, Rutten HJ, Coebergh JWW, de Hingh $1 \mathrm{H}$. Predictors and survival of synchronous peritoneal carcinomatosis of colorectal origin: a population-based study. Int J Cancer. 2011;128:2717-25.

4. Segelman J, Granath F, Holm T, Machado M, Mahteme H, Martling A. Incidence, prevalence and risk factors for peritoneal carcinomatosis from colorectal cancer. Br J Surg. 2012;99:699-705.

5. van Gestel YRBM, de Hingh IHJT, van Herk-Sukel MPP, van Erning FN, Beerepoot LV, Wijsman JH, et al. Patterns of metachronous metastases after curative treatment of colorectal cancer. Cancer Epidemiol. 2014;38:448-54.

6. Chu DZ, Lang NP, Thompson C, Osteen PK, Westbrook KC. Peritoneal carcinomatosis in nongynecologic malignancy. A prospective study of prognostic factors. Cancer. 1989;63:364-7.

7. Sadeghi B, Arvieux C, Glehen O, Beaujard AC, Rivoire M, Baulieux J, et al. Peritoneal carcinomatosis from non-gynecologic malignancies: results of the EVOCAPE 1 multicentric prospective study. Cancer. 2000;88:358-63.

8. Klaver YLB, Simkens LHJ, Lemmens VEPP, Koopman M, Teerenstra S, Bleichrodt RP, et al. Outcomes of colorectal cancer patients with peritoneal carcinomatosis treated with chemotherapy with and without targeted therapy. Eur J Surg Oncol. 2012;38:617-23.

9. van Oudheusden TR, Razenberg LG, van Gestel YR, Creemers GJ, Lemmens $V E$, de Hingh $I H$. Systemic treatment of patients with metachronous peritoneal carcinomatosis of colorectal origin. Sci Rep. 2015;5:18632.

10. Franko J, Shi Q, Goldman CD, Pockaj BA, Nelson GD, Goldberg RM, et al. Treatment of colorectal peritoneal carcinomatosis with systemic chemotherapy: a pooled analysis of north central cancer treatment group phase III trials N9741 and N9841. J Clin Oncol. 2012;30:263-7.

11. Ung L, Chua TC, David LM. Peritoneal metastases of lower gastrointestinal tract origin:a comparative study of patient outcomes following cytoreduction and intraperitoneal chemotherapy. J Cancer Res Clin Oncol. 2013;139:1899-908.

12. Verwaal VJ, Bruin S, Boot H, van Slooten G, van Tinteren H. 8-year follow-up of randomized trial: cytoreduction and hyperthermic intraperitoneal chemotherapy versus systemic chemotherapy in patients with peritoneal carcinomatosis of colorectal cancer. Ann Surg Oncol. 2008;15:2426-32.

13. Glehen O, Kwiatkowski F, Sugarbaker PH, Elias D, Levine EA, De Simone M, et al. Cytoreductive surgery combined with perioperative intraperitoneal chemotherapy for the management of peritoneal carcinomatosis from colorectal cancer: a multi-institutional study. J Clin Oncol. 2004;22:3284-92.

14. Glehen O, Gilly FN, Boutitie F, Bereder JM, Quenet F, Sideris L, et al. Toward curative treatment of peritoneal carcinomatosis from nonovarian origin by cytoreductive surgery combined with perioperative intraperitoneal 
chemotherapy: a multi-institutional study of 1,290 patients. Cancer. 2010; 116:5608-18.

15. Cashin PH, Graf W, Nygren P, Mahteme H. Cytoreductive surgery and intraperitoneal chemotherapy for colorectal peritoneal carcinomatosis: prognosis and treatment of recurrences in a cohort study. Eur J Surg Oncol. 2012:38:509-15.

16. Elias D, Lefevre JH, Chevalier J, Brouquet A, Marchal F, Classe J-M, et al. Complete cytoreductive surgery plus intraperitoneal chemohyperthermia with oxaliplatin for peritoneal carcinomatosis of colorectal origin. J Clin Oncol. 2009;27:681-5.

17. Franko J, Ibrahim Z, Gusani NJ, Holtzman MP, Bartlett DL, Zeh HJ. Cytoreductive surgery and hyperthermic intraperitoneal chemoperfusion versus systemic chemotherapy alone for colorectal peritoneal carcinomatosis. Cancer. 2010;116:3756-62.

18. Hompes D, D'Hoore A, Van Cutsem E, Fieuws S, Ceelen W, Peeters M, et al The treatment of peritoneal carcinomatosis of colorectal cancer with complete cytoreductive surgery and hyperthermic intraperitoneal peroperative chemotherapy (HIPEC) with oxaliplatin: a Belgian multicentre prospective phase II clinical study. Ann Surg Oncol. 2012;19:2186-94.

19. Cavaliere F, Valle M, De Simone M, Deraco M, Rossi CR, Di Filippo F, et al. 120 peritoneal carcinomatoses from colorectal cancer treated with peritonectomy and intra-abdominal chemohyperthermia: a S.IT.T.L.O. multicentric study. Vivo Athens Greece. 2006;20:747-50.

20. Moran B, Cecil T, Chandrakumaran K, Arnold S, Mohamed F Venkatasubramaniam $A$. The results of cytoreductive surgery and hyperthermic intraperitoneal chemotherapy in 1200 patients with peritoneal malignancy. Colorectal Dis. 2015;17:772-8.

21. Verwaal VJ, van Ruth $S$, de Bree E, van Sloothen GW, van Tinteren $H$, Boot $H$, et al. Randomized trial of cytoreduction and hyperthermic intraperitoneal chemotherapy versus systemic chemotherapy and palliative surgery in patients with peritoneal carcinomatosis of colorectal cancer. J Clin Oncol. 2003;21:3737-43

22. Hallam S, Tyler R, Price M, Beggs A, Youssef H. Meta-analysis of prognostic factors for patients with colorectal peritoneal metastasis undergoing cytoreductive surgery and heated intraperitoneal chemotherapy. BJS Open. 2019:3:585-94.

23. Kwakman R, Schrama AM, van Olmen JP, Otten RH, de Lange-de Klerk ES, de Cuba EM, et al. Clinicopathological parameters in patient selection for cytoreductive surgery and hyperthermic intraperitoneal chemotherapy for colorectal cancer metastases: a meta-analysis. Ann Surg. 2016;263:1102-11.

24. Cavaliere F, De Simone M, Virż S, Deraco M, Rossi CR, Garofalo A, et al. Prognostic factors and oncologic outcome in 146 patients with colorectal peritoneal carcinomatosis treated with cytoreductive surgery combined with hyperthermic intraperitoneal chemotherapy: Italian multicenter study S. I.T.I.L.O. Eur J Surg Oncol. 2011;37:148-54.

25. Yonemura Y, Canbay E, Ishibashi H. Prognostic factors of peritoneal metastases from colorectal cancer following cytoreductive surgery and perioperative chemotherapy. Sci World J. 2013;2013:978394.

26. Elias $D$, Mariani A, Cloutier $A-S$, Blot $F$, Goéré $D$, Dumont $F$, et al. Modified selection criteria for complete cytoreductive surgery plus HIPE $C$ based on peritoneal cancer index and small bowel involvement for peritoneal carcinomatosis of colorectal origin. Eur J Surg Oncol. 2014;40: 1467-73.

27. Sugarbaker PH. Peritonectomy procedures. Ann Surg. 1995;221:29-42.

28. Jacquet $\mathrm{P}$, Sugarbaker $\mathrm{PH}$. Clinical research methodologies in diagnosis and staging of patients with peritoneal carcinomatosis. Cancer Treat Res. 1996; 82:359-74.

29. Turaga K, Levine E, Barone R, Sticca R, Petrelli N, Lambert L, et al. Consensus guidelines from The American Society of Peritoneal Surface Malignancies on standardizing the delivery of hyperthermic intraperitoneal chemotherapy (HIPEC) in colorectal cancer patients in the United States. Ann Surg Oncol. 2014;21:1501-5.

30. Clavien PA, Barkun J, de Oliveira ML, Vauthey JN, Dindo D, Schulick RD, et al. The Clavien-Dindo classification of surgical complications: five-year experience. Ann Surg. 2009;250:187-96.

31. Shida D, Yoshida T, Tanabe T, Tsukamoto S, Ochiai H, Kanemitsu Y. Prognostic impact of RO resection and targeted therapy for colorectal cancer with synchronous peritoneal metastasis. Ann Surg Oncol. 2018;25: 1646-53.

32. Piso P, Nedelcut SD, Rau B, Königsrainer A, Glockzin G, Ströhlein MA, et al. Morbidity and mortality following cytoreductive surgery and hyperthermic intraperitoneal chemotherapy: data from the DGAV StuDoQ registry with 2149 consecutive patients. Ann Surg Oncol. 2019;26:148-54.

33. Newton AD, Bartlett EK, Karakousis GC. Cytoreductive surgery and hyperthermic intraperitoneal chemotherapy: a review of factors contributing to morbidity and mortality. J Gastrointest Oncol. 2016;7:99-111.

34. Ihemelandu C, Sugarbaker PH. Management for peritoneal metastasis of colonic origin: role of cytoreductive surgery and perioperative intraperitoneal chemotherapy: a single institution's experience during two decades. Ann Surg Oncol. 2017;24:898-905.

35. Sugarbaker PH. Peritoneal metastases from gastrointestinal cancer. Curr Oncol Rep. 2018;20:62

36. Winer J, Zenati M, Ramalingam L, Jones $\mathrm{H}$, Zureikat A, Holtzman $\mathrm{M}$, et al. Impact of aggressive histology and location of primary tumor on the efficacy of surgical therapy for peritoneal carcinomatosis of colorectal origin. Ann Surg Oncol. 2014;21:1456-62.

37. Elias D, Gilly F, Boutitie F, Quenet F, Bereder J-M, Mansvelt B, et al. Peritoneal colorectal carcinomatosis treated with surgery and perioperative intraperitoneal chemotherapy: retrospective analysis of 523 patients from a multicentric French study. J Clin Oncol. 2010;28:63-8.

38. Yan TD, Morris DL. Cytoreductive surgery and perioperative intraperitoneal chemotherapy for isolated colorectal peritoneal carcinomatosis: experimental therapy or standard of care? Ann Surg. 2008;248:829-35.

39. Rivard JD, McConnell YJ, Temple WJ, Mack LA. Cytoreduction and heated intraperitoneal chemotherapy for colorectal cancer: are we excluding patients who may benefit? J Surg Oncol. 2014;109:104-9.

40. Goéré D, Souadka A, Faron M, Cloutier AS, Viana B, Honoré C, et al. Extent of colorectal peritoneal carcinomatosis: attempt to define a threshold above which HIPEC does not offer survival benefit: a comparative study. Ann Surg Oncol. 2015;22:2958-64.

41. Faron $M$, Macovei R, Goéré $D$, Honoré $C$, Benhaim L, Elias D. Linear relationship of peritoneal cancer index and survival in patients with peritoneal metastases from colorectal cancer. Ann Surg Oncol. 2016;23:1149.

42. Bagante F, Spolverato G, Beal E, Merath K, Chen Q, Akgül O, et al. Impact of histological subtype on the prognosis of patients undergoing surgery for colon cancer. J Surg Oncol. 2018;117:1355-63.

43. Green JB, Timmcke AE, Mitchell WT, Hicks TC, Gathright JB, Ray JE. Mucinous carcinoma--just another colon cancer? Dis Colon Rectum. 1993;36:49-54.

44. Langner C, Harbaum L, Pollheimer MJ, Kornprat P, Lindtner RA, Schlemmer A, et al. Mucinous differentiation in colorectal cancer-indicator of poor prognosis? Histopathology. 2012;60:1060-72.

45. Le QT, Fu KK, Kaplan M, Terris DJ, Fee WE, Goffinet DR. Treatment of maxillary sinus carcinoma: a comparison of the 1997 and 1977 American Joint Committee on cancer staging systems. Cancer. 1999;86:1700-11.

46. Chua TC, Pelz JOW, Kerscher A, Morris DL, Esquivel J. Critical analysis of 33 patients with peritoneal carcinomatosis secondary to colorectal and appendiceal signet ring cell carcinoma. Ann Surg Oncol. 2009;16:2765-70.

47. Verwaal VJ, van Tinteren H, van Ruth S, Zoetmulder FA. Predicting the survival of patients with peritoneal carcinomatosis of colorectal origin treated by aggressive cytoreduction and hyperthermic intraperitoneal chemotherapy. Br J Surg. 2004;91:739-46.

48. Pelz JOW, Chua TC, Esquivel J, Stojadinovic A, Doerfer J, Morris DL, et al. Evaluation of best supportive care and systemic chemotherapy as treatment stratified according to the retrospective peritoneal surface disease severity score (PSDSS) for peritoneal carcinomatosis of colorectal origin. BMC Cancer. 2010;10:689.

49. Van Sweringen HL, Hanseman DJ, Ahmad SA, Edwards MJ, Sussman JJ. Predictors of survival in patients with high-grade peritoneal metastases undergoing cytoreductive surgery and hyperthermic intraperitoneal chemotherapy. Surgery. 2012;152:617-24 discussion 624-625.

50. Hentzen JEKR, Rovers KP, Kuipers $H$, van der Plas WY, Been LB, Hoogwater $\mathrm{FJH}$, et al. Impact of synchronous versus metachronous onset of colorectal peritoneal metastases on survival outcomes after cytoreductive surgery (CRS) with hyperthermic intraperitoneal chemotherapy (HIPEC): a multicenter, retrospective, observational study. Ann Surg Oncol. 2019;26: 2210-21.

51. Braam HJ, van Oudheusden TR, de Hingh IHJT, Nienhuijs SW, Boerma D, Wiezer MJ, et al. Patterns of recurrence following complete cytoreductive surgery and hyperthermic intraperitoneal chemotherapy in patients with peritoneal carcinomatosis of colorectal cancer. J Surg Oncol. 2014;109:841-7. 
52. Chua TC, Yan TD, Ng KM, Zhao J, Morris DL. Significance of lymph node metastasis in patients with colorectal cancer peritoneal carcinomatosis. World J Surg. 2009;33:1488-94.

53. Baumgartner JM, Tobin L, Heavey SF, Kelly KJ, Roeland EJ, Lowy AM.

Predictors of progression in high-grade appendiceal or colorectal peritoneal carcinomatosis after cytoreductive surgery and hyperthermic intraperitoneal chemotherapy. Ann Surg Oncol. 2015;22:1716-21.

54. Simkens GA, Rovers KP, Nienhuijs SW, de Hingh IH. Patient selection for cytoreductive surgery and HIPEC for the treatment of peritoneal metastases from colorectal cancer. Cancer Manag Res. 2017;9:259-66.

55. Heald RJ, Husband EM, Ryall RD. The mesorectum in rectal cancer surgery-the clue to pelvic recurrence? Br J Surg. 1982;69:613-6.

56. Hohenberger W, Weber K, Matzel K, Papadopoulos T, Merkel S. Standardized surgery for colonic cancer: complete mesocolic excision and central ligation--technical notes and outcome. Colorectal Dis. 2009;11:354-64 discussion 364-365.

57. Quenet F, Elias D, Roca L, et al. A UNICANCER phase III trial of hyperthermic intra-peritoneal chemotherapy (HIPEC) for colorectal peritoneal carcinomatosis (PC): PRODIGE 7. J Clin Oncol. 2018;36:3503.

\section{Publisher's Note}

Springer Nature remains neutral with regard to jurisdictional claims in published maps and institutional affiliations.

Ready to submit your research? Choose BMC and benefit from:

- fast, convenient online submission

- thorough peer review by experienced researchers in your field

- rapid publication on acceptance

- support for research data, including large and complex data types

- gold Open Access which fosters wider collaboration and increased citations

- maximum visibility for your research: over $100 \mathrm{M}$ website views per year

At $\mathrm{BMC}$, research is always in progress.

Learn more biomedcentral.com/submissions 